\title{
PREDICTION OF TRAFFIC SIGN VANDALISM THAT OBSTRUCTS CRITICAL MESSAGES TO DRIVERS
}

\author{
Majid Khalilikhah, Kevin Heaslip \\ Dept of Civil and Environmental Engineering, Virginia Polytechnic Institute and State University, \\ United States
}

Submitted 11 December 2015; resubmitted 25 March 2016; accepted 18 April 2016;

published online 01 March 2017

\begin{abstract}
A critical deficiency in any one or a combination of three transportation system characteristics: the driver, roadway, or vehicle can contribute to an elevated crash risk for the motoring public. Traffic signs often convey critical information to drivers. However, traffic signs are only effective when clearly visible and legible. Traffic sign vandalism that is exclusively the results of humans causes both sign legibility and visibility to deteriorate. Transportation agencies spend a significant amount of money to repair or replace vandalized signs. This study was conducted to identify which traffic signs are more vulnerable to vandalism. To do this, a mobile-based vehicle collected data of over 97000 traffic signs managed by the Utah Department of Transportation (UDoT), US. The vandalized signs were identified by a trained operator through inspection of daytime digital images taken of each individual sign. Location data obtained from online sources combined with the traffic sign data were imported into ArcGIS to acquire localized conditions for each individual sign. According to the chi-square test results, the association between vandalism and traffic sign attributes and localized conditions, including background color, size, mount height, exposure, land cover, and road type was evident. After employing the random forests model, the most important factors in making signs vulnerable to vandalism were identified.
\end{abstract}

Keywords: transportation infrastructure; traffic sign vandalism; mobile-based data collection; mobile LiDAR; digital imaging; geographic information system; random forests.

\section{Introduction}

A variety of factors associated with drivers, vehicles and the roadway contribute to the likelihood of crashes. Transportation agencies continually make efforts to design safety improvements that will reduce such outcomes, with particular concern for fatal and serious injury crashes (Baratian-Ghorghi et al. 2015). Of all types of transportation infrastructure, traffic signs are the most frequent visual aids. Their task is providing safer traffic environments through regulating, warning, or guiding road users. The placement of key traffic signs, such as stop signs, yield signs, and speed limits, increases traffic safety (Borowsky et al. 2008). Previous studies showed that drivers behavior can be dramatically influenced after the placement of yield to pedestrian at crosswalks signs (Ellis et al. 2015), work-zone warning signs and school zone signs (Strawderman et al. 2015).

In order for road users to comprehend traffic signs, high legibility and visibility are critical (Ye et al. 2014).
The overall legibility of a sign declines when the face of a sign is damaged (Boggs et al. 2013). Depending on the form of damage, the effects on legibility vary considerably. A number of sign damage forms are exclusively the result of humans. The overall day and night-time legibility of the sign can be affected by vandalism (Evans et al. 2012). In addition, tremendous amounts of money are spent to repair or replace vandalized signs (Harris 1992). Types of human vandalism include shooting paintballs, shooting bullets, throwing beer bottles, putting stickers on signs, and painting graffiti on signs. Although traffic sign vandalism has become a serious problem for traffic agencies (Chadda, Carter 1983) few studies are conducted that focus on this issue. Previous studies have estimated the costs of sign vandalism (Smith, Simodynes 2000), developed methods for sign vandalism detection (Mueller 1995), and examined the effects of releasing information in the media to reduce sign vandalism (Ellison 1996). A study examined the association between

Corresponding author: Majid Khalilikhah

E-mail: majidk@vt.edu 
traffic sign vandalism and demographics of local population (Khalilikhah et al. 2016).

The countermeasures against vandalism have been discussed with regard to the form of sign vandalism, including utilizing more resistant materials to construct signs, mounting signs higher, applying penalty notices to signs, and using public information campaigns (Picha 1997; Perkins, Barton 1997). However, it is necessary to identify traffic signs that are more vulnerable to vandalism before installing them. This research was conducted to accomplish this goal. To do so, mobile-based data of 97000 traffic signs managed by the Utah Department of Transportation (UDoT) was collected. Mobile-based data provided sign attributes data, including background color, sign size, and mount height. The vandalized signs were identified by an operator through inspection of daytime digital images taken of each individual sign. Location data obtained from online sources combined with the traffic sign data was imported into ArcGIS to acquire localized conditions for each individual sign. The random forests model was employed to determine what traffic signs were more likely to be damaged by vandals.

\section{Traffic Sign Data Description}

\subsection{Background}

Traffic signs convey critical information to drivers. The process of conveying messages involves an interaction between signs and drivers. Some studies focused on the road user characteristics to investigate the under-

a)

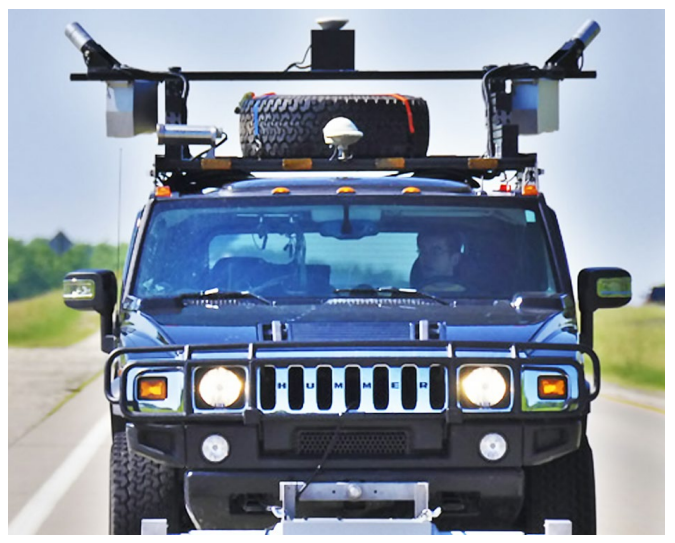

b) standability and comprehensibility of traffic signs. Other studies examined sign visibility and legibility with regard to sign attributes, location, and climate conditions (Bullough et al. 2010; Khalilikhah, Heaslip 2016a). Recently, a study examined the effectiveness of roadside signs in comparison to the in-vehicle auditory traffic information (Ma et al. 2016). Khalilikhah et al. (2015a), Khalilikhah, Heaslip (2016b) examined the effects of emissions of sign visibility and legibility. Multiple studies were performed focusing on the assessment and management of traffic signs (Ré, Carlson 2012; Balali, Golparvar-Fard 2015). Another study discussed the design of traffic signs (Stanić, Vujin 2005). However, little research exists regarding traffic sign vandalism. The objective of this research is to determine what types of traffic signs are more vulnerable to traffic sign vandalism.

\subsection{Data Collection Method}

In 2012, a mobile-based data collection effort was conducted in Utah to measure all traffic signs under the jurisdiction of the Utah Department of Transportation (UDoT). This comprehensive approach was carried out by an instrumented vehicle driven at freeway speeds that collected asset data on the roadway in real time (Fig. 1). The sensors on the vehicle included: a LiDAR sensor, a laser road imaging system, a laser rut measurement system, a laser crack measurement system, a road surface profiler, and a position orientation system. In conclusion, data of over 97000 traffic signs was collected on roadways along over 6000 miles of state routes and interstates. In addition, imaging technologies were integrated to automatically collect high-resolution detailed images from the assets. After conducting postprocessing analysis by survey, the desired sign attributes data were derived, including location (latitude and longitude), size, orientation, and mount height. An operator also examined the captured daytime digital images, and noted damaged or deteriorated traffic signs throughout the entire data set (Khalilikhah et al. 2015b).

\subsection{Sign Damage Categories}

Data analysis conducted by the authors showed that almost $7 \%$ of all measured signs were damaged. Traffic signs exhibited various forms of damage, including being bent, delaminated, dented, dirty, faded, fallen, defaced by graffiti or paint, obstructed, rusty, and covered by stickers. Either humans or nature could have caused

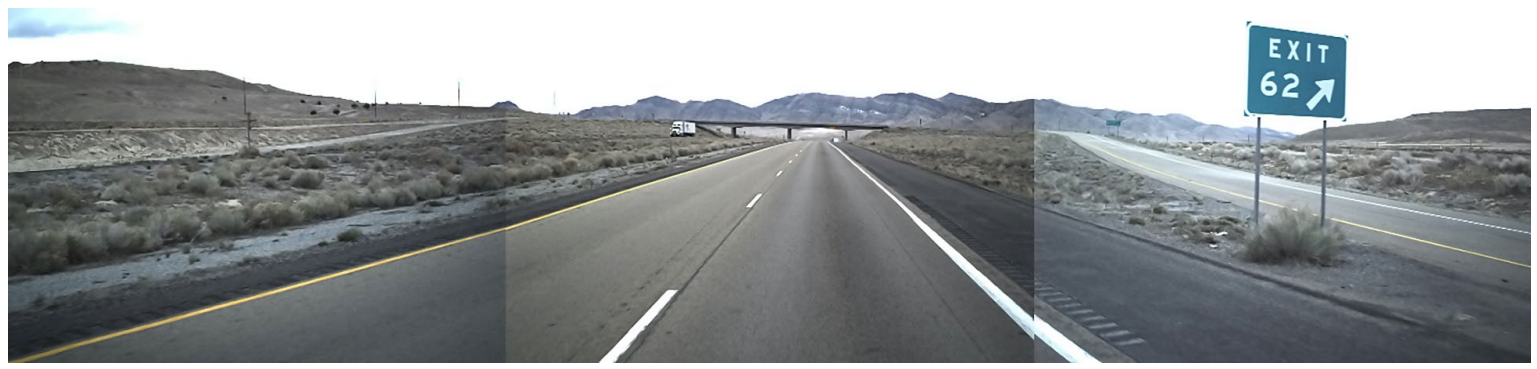

Fig. 1. Mobile-based data collection: a - equipped vehicle (source: http://mandli.com); b - taking image of traffic signs (source: http://168.178.125.102/roadview.asp?Route=0080P\&Mile=61.6) 


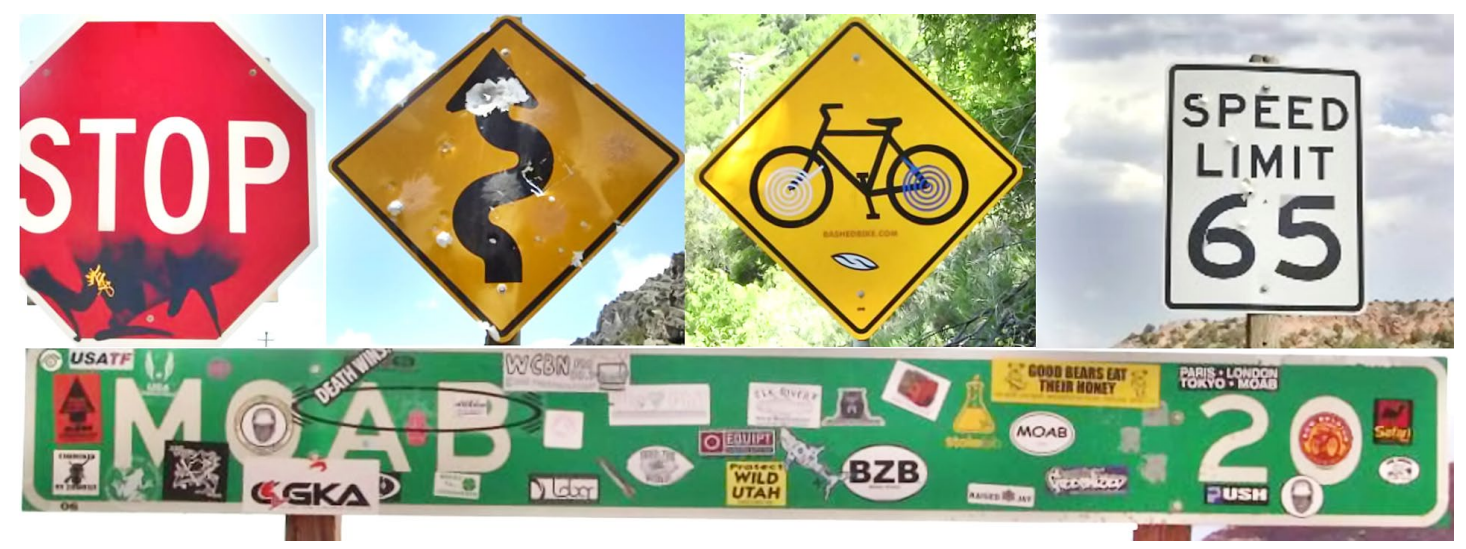

Fig. 2. Samples of traffic sign vandalism (source: photos taken by our research team)

these forms of damage. Ultimately, we categorized damage forms into two groups: vandalism or naturally occurrences. To do so, we used a sample data set collected by our research team in the field, including photos taken of about 1700 traffic signs. Vandalism included any deliberate damage to the sign face, including stickers, painting, dents, gunshots, and or graffiti, as shown in Fig. 2. Natural damage forms consisted of deterioration formed over timte, damage forms were the result of weather or other natural factors, or damage unintentionally caused by humans. The locations of the vandalized signs are shown in Fig. 3.

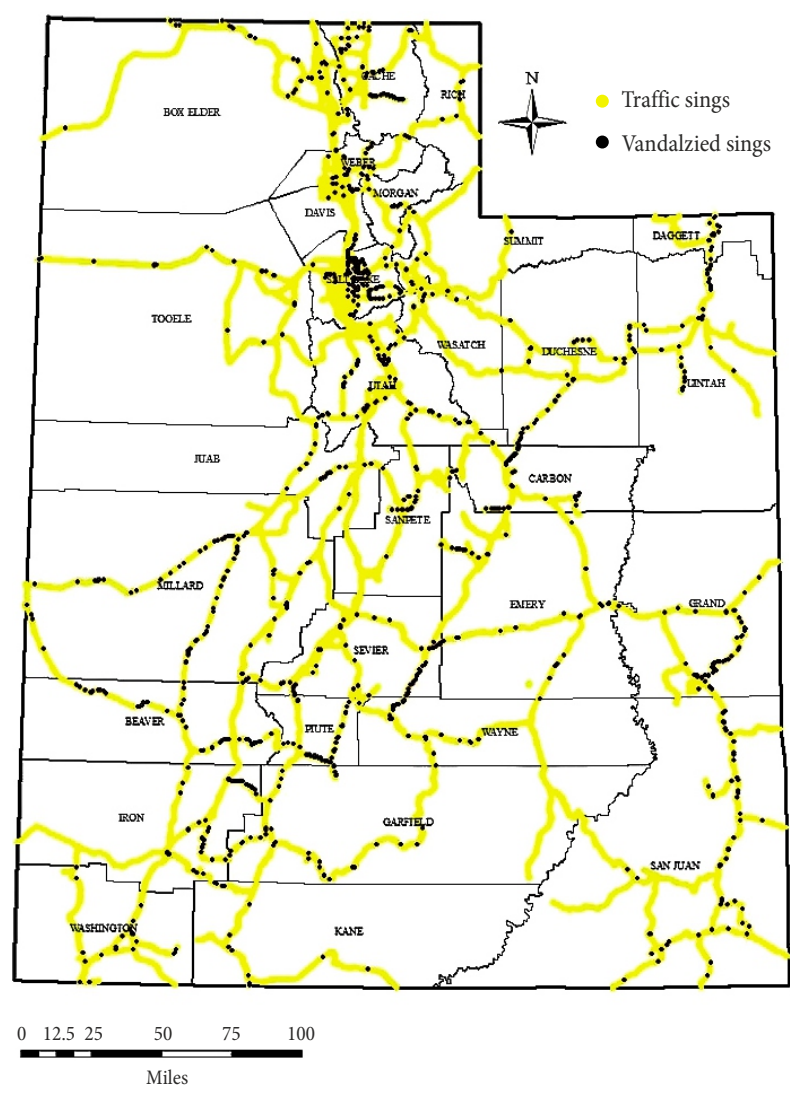

Fig. 3. Locations of vandalized traffic signs in Utah

\section{Data Analysis}

\subsection{Sign Vandalism by Manual on Uniform Traffic Control Devices (MUTCD) Type}

Table 1 provides a summary of the vandalized traffic signs based on the Manual on Uniform Traffic Control Devices (MUTCD) types. The Manual of Traffic Signs (Moeur 2014) was used to list traffic signs based on their type and sub-type. Respectively, regulatory, warning, marker, and guide signs made up almost $18,20,20$, and $23 \%$ of over 97000 measured traffic signs. As a whole, warning signs, by far, exhibited the highest vandalism rate. Of vandalized signs, $53 \%$ were warning signs. With regard to the percentage of sign vandalism, turn and curve warning signs showed the highest rates, comprising approximately $30 \%$ of vandalized signs. $8 \%$ of the vandalized signs were advance warning/crossing, 7\% were speed regulation signs and $9 \%$ were object markers. Interestingly, nearly $11 \%$ of vandalized signs were signs that deal with speed limits (speed regulation and advisory speed signs).

Based on the sign legend type, vandalized signs were categorized into four groups: text, symbol, arrow, and text/symbol/arrow. To be categorized as a text sign, these signs need words or digits to accomplish their tasks. Examples of text signs included speed limit signs (R2-1), mileposts (D10-1), and supplemental distance signs (W16-2 and 3). Symbol signs consisted of those that use symbols, rather than words or digits to interact with road users. Examples included school signs (S1-1), no pedestrian signs (R9-3a), and cattle or deer crossing signs (W11-3 and 4). The arrow category included any traffic signs employing arrows to regulate, warn, or guide drivers. For example, straight optional lane signs (R3-6L or R), reverse turn signs (W1-3L or R), and arrow auxiliary signs (M6-1L or R). The data also identified a final group of signs that included a combination of text, symbols, and arrows. These signs were included in the text/symbol/arrow grouping, such as do not enter signs (R5-1), stop ahead signs (W3-1), and destination with distance signs (D1-1, 2 and 3). Ultimately, it was found that arrow signs had the highest rate of vandalism, followed by text signs (Fig. 4). 
Table 1. Summary of vandalized signs by MUTCD type

\begin{tabular}{|c|c|c|c|c|c|c|c|}
\hline \multicolumn{2}{|c|}{ Traffic sign } & \multirow{2}{*}{ MUTCD code } & \multicolumn{4}{|c|}{ \# of signs } & \multirow{2}{*}{$\%$} \\
\hline Type & Name & & Text & Symbol & Arrow & $\mathrm{T} / \mathrm{S} / \mathrm{A}$ & \\
\hline \multirow{9}{*}{ 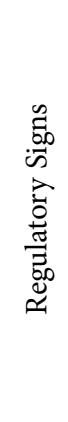 } & Stop and yield & R1 series & 32 & - & - & - & 2.1 \\
\hline & Speed regulation & R2 series & 106 & - & - & - & 7.1 \\
\hline & Turn and land use & R3 series & 5 & - & 5 & 5 & 1.0 \\
\hline & Movement regulation & R4 series & 1 & - & 6 & 4 & 0.7 \\
\hline & Selective exclusion & R5 series & 1 & 1 & - & 1 & 0.2 \\
\hline & One way & R6 series & - & - & - & 3 & 0.2 \\
\hline & Pedestrian and bicycle & R9 series & - & 1 & - & - & 0.1 \\
\hline & Traffic signal & R10 series & 2 & - & - & 2 & 0.3 \\
\hline & Road closed & R11 series & 2 & - & - & - & 0.1 \\
\hline \multirow{13}{*}{ 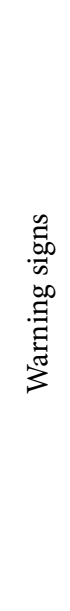 } & Turn and curve & W1 series & - & - & 456 & - & 30.4 \\
\hline & Intersection & W2 series & - & - & 22 & - & 1.5 \\
\hline & Advance traffic control & W3 series & 1 & - & - & 15 & 1.1 \\
\hline & Merge and lane transition & W4 series & - & - & 32 & - & 2.1 \\
\hline & Divided highway & W6 series & - & - & 6 & - & 0.4 \\
\hline & Hill & W7 series & 5 & 1 & - & 6 & 0.8 \\
\hline & Pavement condition & W8 series & 15 & 2 & - & - & 1.1 \\
\hline & Railroad and light rail & W10 series & - & - & - & 2 & 0.1 \\
\hline & Advance warning / Crossing & W11 series & - & 123 & - & - & 8.2 \\
\hline & Low Clearance & W12 series & - & - & 3 & 1 & 0.3 \\
\hline & Advisory Speed & W13 series & 54 & - & - & - & 3.6 \\
\hline & Dead end / No outlet / No passing & W14 series & 1 & - & - & - & 0.1 \\
\hline & Supplemental plaques & W16 series & 30 & - & 19 & - & 3.3 \\
\hline \multirow{6}{*}{ 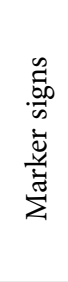 } & Route markers & M1 series & 52 & - & - & - & 3.5 \\
\hline & Junction signs & M2 series & 5 & - & - & - & 0.3 \\
\hline & Cardinal direction auxiliaries & M3 series & 5 & - & - & - & 0.3 \\
\hline & Advance turn auxiliaries & M5 series & - & - & 2 & - & 0.1 \\
\hline & Directional arrow auxiliaries & M6 series & - & - & 37 & - & 2.5 \\
\hline & Object markers & OM series & - & - & 138 & - & 9.2 \\
\hline \multirow{11}{*}{ 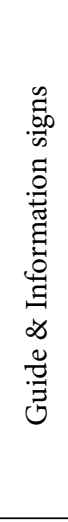 } & Destination & D1 series & - & - & - & 36 & 2.4 \\
\hline & Distance & D2 series & 14 & - & - & - & 0.9 \\
\hline & Recreational & D7 series & 9 & - & - & 15 & 1.6 \\
\hline & General services & D9 series & - & 4 & - & - & 0.3 \\
\hline & Mileposts & D10 series & 70 & - & - & - & 4.7 \\
\hline & Crossover / Freeway entrance & D13 series & 2 & - & - & - & 0.1 \\
\hline & Interchange advance & E1 series & 2 & - & - & - & 0.1 \\
\hline & Exit gore & E5 series & - & - & - & 2 & 0.1 \\
\hline & Destination & E6 series & - & - & - & 10 & 0.7 \\
\hline & Destination & E10 series & - & - & - & 4 & 0.3 \\
\hline & General information & I series & 11 & - & - & - & 0.7 \\
\hline \multicolumn{2}{|c|}{ School signs } & $\mathrm{S} 1, \mathrm{~S} 3$ and $\mathrm{S} 5$ series & 11 & 6 & - & - & 1.1 \\
\hline \multicolumn{3}{|c|}{ Other signs } & 59 & 20 & 1 & 14 & 6.3 \\
\hline
\end{tabular}

The question of interest was if traffic sign vandalism corresponds to specific types of signs. In other words, the authors conducted this research to figure out what attributes of traffic signs make them more likely to get vandalized. Questions to be answered include:
- do vandals select traffic signs based on sign color, size, or mount height?

- do localized conditions, such as exposure (urban or rural) and road type (major or ramp) make them more vulnerable to vandalism?

The next sections find answers for these questions. 


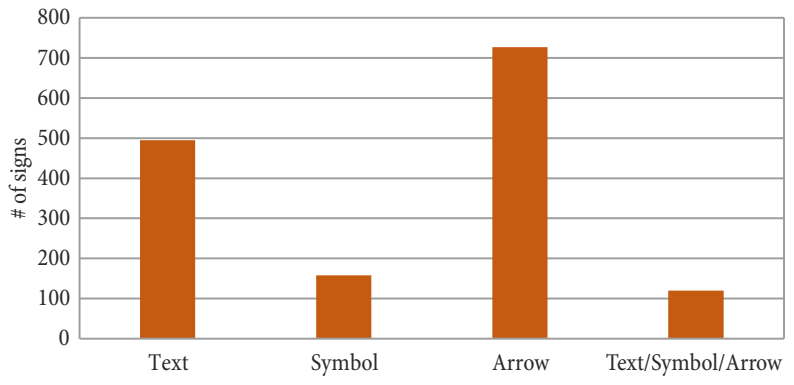

Fig. 4. Number of vandalized traffic signs by legend type

\subsection{Signs Attributes}

The association between traffic signs attributes and localized conditions and vandalism rates was tested using chi-square test. A summary of the association between the sign attributes and sign vandalism is provided in the following.

\subsubsection{Sign Background Color}

Green, red, white, yellow, black, blue, orange, and brown were the observed background colors of surveyed signs. Respectively, 22, 23 and 29\% of the surveyed signs were green, white, and yellow, while the other colors collectively made up only $26 \%$ of the total. Table 2 depicts a summary of the sign vandalism rates based on the sign background color. Warning signs are typically yellow (DoT 2012). Thus, yellow signs tend to have a relatively higher vandalism rate. According to the results of the chi-square test, there is strong evidence of an association between sign vandalism rate and sign background color.

Table 2. Traffic sign vandalism by color

\begin{tabular}{|l|c|c|c|c|}
\hline \multirow{2}{*}{ Color } & \multirow{2}{*}{ \# of signs } & \multicolumn{2}{|c|}{ Vandalism } & \multirow{2}{*}{ Vandalized [\%] } \\
\cline { 3 - 4 } & & yes & no & \\
\hline Green & 21112 & 145 & 20967 & 0.69 \\
\hline Red & 1937 & 33 & 1904 & 1.70 \\
\hline White & 28610 & 240 & 28370 & 0.84 \\
\hline Yellow & 22844 & 843 & 22001 & 3.69 \\
\hline Others & 22811 & 239 & 22572 & 1.05 \\
\hline Chi-square test statistic $=926.65$ \\
\hline
\end{tabular}

\subsubsection{Sign Length and Width}

To ensure adequate message comprehensibility, the appropriate size of each sign should be determined based on the task of sign and the prevailing traffic speed on the road (VDoT 2011). Tables 3 and 4 display the corresponding sign vandalism ratings for each category of length and width. Generally speaking, the percentage of vandalized signs changes little among different categories of length or width, with the exception of signs with width from 24 to 36 inches and length of between 30 and 40 inches, which is mostly the size of warning signs. The chi-square value is statistically significant. Thus, there is evidence of an association between sign size and vandalism rate.
Table 3. Traffic sign vandalism by width

\begin{tabular}{|c|c|c|c|c|}
\hline \multirow{2}{*}{$\begin{array}{c}\text { Sign width } \\
\text { [in] }\end{array}$} & \multirow{2}{*}{ \# of signs } & \multicolumn{2}{|c|}{ Vandalism } & \multirow{2}{*}{ Vandalized [\%] } \\
\cline { 3 - 4 } & & yes & no & \\
\hline$<18$ & 19350 & 232 & 19118 & 1.20 \\
\hline $18-24$ & 33720 & 422 & 33298 & 1.25 \\
\hline $24-36$ & 22713 & 635 & 22078 & 2.80 \\
\hline $36-54$ & 8421 & 113 & 8308 & 1.34 \\
\hline$>54$ & 13110 & 98 & 13012 & 0.75 \\
\hline
\end{tabular}

Table 4. Traffic sign vandalism by length

\begin{tabular}{|c|c|c|c|c|}
\hline \multirow{2}{*}{$\begin{array}{c}\text { Sign length } \\
\text { [in] }\end{array}$} & \multirow{2}{*}{$\begin{array}{c}\text { \# of } \\
\text { signs }\end{array}$} & \multicolumn{2}{|c|}{ Vandalism } & \multirow{2}{*}{ Vandalized [\%] } \\
\cline { 3 - 4 } & 24112 & 170 & 23942 & 0.71 \\
\hline$<20$ & 22051 & 216 & 21835 & 0.98 \\
\hline $20-30$ & 37309 & 970 & 36339 & 2.60 \\
\hline $30-40$ & 7903 & 105 & 7798 & 1.33 \\
\hline $40-60$ & 5939 & 39 & 5900 & 0.66 \\
\hline$>60$ & nes & \\
\hline Chi-square test statistic $=465.44$ \\
\hline$p$-value $<0.0001$
\end{tabular}

\subsubsection{Sign Mount Height}

According to the summary of sign vandalism by mount height (Table 5), signs placed higher were less likely to get vandalized. For signs placed 10 feet or more above the road, the vandalism rate was only $0.12 \%$. Based on the results of the chi-square test, there is evidence of an association between sign vandalism rate and mount height.

Table 5. Traffic sign vandalism by mount height

\begin{tabular}{|c|c|c|c|c|}
\hline \multirow{2}{*}{$\begin{array}{c}\text { Sign height } \\
\text { above road [ft] }\end{array}$} & \multirow{2}{*}{$\begin{array}{c}\text { s of } \\
\text { signs }\end{array}$} & \multicolumn{2}{|c|}{ Vandalism } & \multirow{2}{*}{ Vandalized [\%] } \\
\cline { 3 - 4 } & 17160 & 272 & 16888 & 1.59 \\
\hline$<5$ & 25707 & 632 & 25075 & 2.46 \\
\hline $5-7$ & 24020 & 427 & 23593 & 1.78 \\
\hline $7-8$ & 17718 & 154 & 17564 & 0.87 \\
\hline $8-10$ & 12709 & 15 & 12694 & 0.12 \\
\hline$>10$ & \multicolumn{5}{|l|}{} \\
\hline Chi-square test statistic $=373.93$ \\
\hline
\end{tabular}

\subsubsection{Exposure}

Our recent study reported that the sign vandalism rate for rural signs was greater than that of urban signs (Khalilikhah et al. 2016). We defined a variable called sign exposure (urban or rural) with respect to the area that the traffic sign was installed. To obtain sign exposure data, the Geographic Information Database of Utah's Automated Geographic Reference Center (Utah AGRC 2015) website was used. Then, rural and urban signs were identified using ArcGIS. A summary of 
the traffic signs vandalism by exposure is provided in Table 6. As seen in the table, the number of vandalized signs for rural exposure is indeed higher than for urban areas. The chi-square value was also statistically significant. Therefore, the association between sign exposure and number of vandalized signs was evident.

Table 6. Traffic sign vandalism by sign exposure

\begin{tabular}{|c|c|c|c|c|}
\hline \multirow{2}{*}{ Exposure } & \multirow{2}{*}{ \# of signs } & \multicolumn{2}{|c|}{ Vandalism } & \multirow{2}{*}{ Vandalized [\%] } \\
\cline { 3 - 4 } & & yes & no & \\
\hline Urban & 46611 & 410 & 46201 & 0.88 \\
\hline Rural & 50703 & 1090 & 49613 & 2.15 \\
\hline Chi-square test statistic $=257.32$ \\
\hline$p$-value $<0.0001$ \\
\hline
\end{tabular}

To have a better sense of the environment surrounding these signs, we obtained 16-category land cover classification data from the National Land Cover Database 2011 - NLCD 2011 (MRLC 2011). NLCD 2011 applied the classifications consistently across the country at a spatial resolution of 1000 feet. It categorized land cover into the following groups:

- water (open water, perennial ice/snow);

- developed (open space, low intensity, medium intensity, high intensity);

- barren land (rock/sand/clay);

- forest (deciduous, evergreen, mixed);

- shrubland (dwarf scrub, shrub/scrub);

- herbaceous (grassland/herbaceous, sedge/herbaceous, lichens, moss);

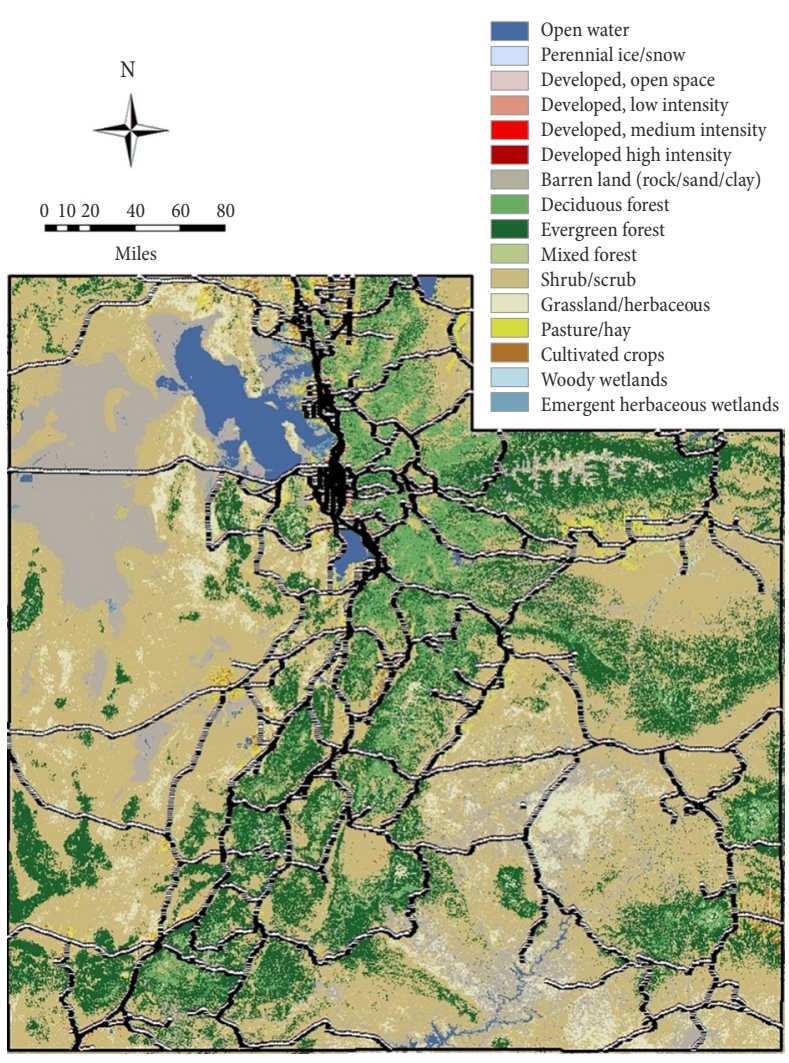

Fig. 5. Locations of traffic signs by land cover
- planted/cultivated (pasture/hay, cultivated crops);

- wetlands (woody wetlands, emergent herbaceous wetlands).

To obtain the type of land cover for each individual sign, we created a raster data using ArcGIS (Fig. 5). Then, we extracted the land cover type surrounding the signs from the raster data. The results of this extraction are summarized in Table 7. As expected, the result of the chi-square test showed evidence of an association between the vandalism rate and type of land cover. Signs installed in areas labeled as forest had the greatest rate of vandalism. Importantly, almost $84 \%$ of the UDoT's signs were located in developed areas. By focusing upon developed areas, another trend could be observed: open space areas showed the highest rate of vandalism, and the lowest rate was exhibited by high-intensity areas.

Table 7. Traffic sign vandalism by land cover

\begin{tabular}{|c|c|c|c|c|}
\hline \multirow{2}{*}{ Land cover } & \multirow{2}{*}{$\begin{array}{l}\text { \# of } \\
\text { signs }\end{array}$} & \multicolumn{2}{|c|}{ Vandalism } & \multirow{2}{*}{$\begin{array}{c}\text { Vandalized } \\
{[\%]}\end{array}$} \\
\hline & & yes & no & \\
\hline Developed-open space & 26956 & 564 & 26392 & 2.09 \\
\hline $\begin{array}{l}\text { Developed-low } \\
\text { intensity residential }\end{array}$ & 24560 & 367 & 24193 & 1.49 \\
\hline $\begin{array}{l}\text { Developed-medium } \\
\text { intensity residential }\end{array}$ & 19777 & 222 & 19555 & 1.12 \\
\hline $\begin{array}{l}\text { Developed-high } \\
\text { intensity residential }\end{array}$ & 10843 & 107 & 10736 & 0.99 \\
\hline Bare rock/sand/clay & 194 & 4 & 190 & 2.06 \\
\hline Forest & 1658 & 46 & 1612 & 2.77 \\
\hline Shrub/scrub & 9980 & 163 & 9817 & 1.63 \\
\hline Grasslands/herbaceous & 553 & 8 & 545 & 1.45 \\
\hline Planted/cultivated & 2183 & 13 & 2170 & 0.60 \\
\hline Wetlands & 610 & 6 & 604 & 0.98 \\
\hline \multicolumn{5}{|c|}{ Chi-square test statistic $=130.77$} \\
\hline \multicolumn{5}{|l|}{$p$-value $<0.0001$} \\
\hline
\end{tabular}

\subsubsection{Road type}

The (Utah AGRC 2015) data set was used to extract the type of road that traffic sign was installed on. To do so, ArcGIS was employed and ultimately traffic signs were categorized into two groups based on where they were placed. Category one was major road signs ( $87 \%$ of the measured signs), and category two was signs placed in ramps, rest areas, or turnarounds (13\% of the measured signs) (Table 8). After running the chi-square test, the association between road type and sign vandalism rate was evident. The rate of sign vandalism for major road signs was higher than the other signs.

Table 8 . Traffic sign vandalism by road type

\begin{tabular}{|l|c|c|c|c|}
\hline \multirow{2}{*}{ Road type } & \multirow{2}{*}{$\begin{array}{c}\text { \# of } \\
\text { signs }\end{array}$} & \multicolumn{2}{|c|}{ Vandalism } & \multirow{2}{*}{ Vandalized [\%] } \\
\cline { 3 - 4 } & 84423 & 1412 & 83011 & 1.67 \\
\hline Major & 8428 & No & \\
\hline Ramp (on/off) & 12891 & 88 & 12803 & 0.68 \\
\hline Chi-square test statistic $=71.55$ \\
\hline$p$-value $<0.0001$ \\
\hline
\end{tabular}




\subsection{Modeling}

To identify traffic signs that were more likely to get vandalized, developing statistical models that could yield the desired results was needed. Through analysis of the collected data, it was observed that 1500 of over 97000 measured traffic signs were vandalized; this is approximately $1.5 \%$ of UDoT's signs. Thus, the response variable was extremely biased. In addition, the relationships among the explanatory variables was also thoroughly complex. The unknown, but likely, nonlinear relation between response and predictors was also expected. Besides, the data structure of multiple explanatory variables was enormously varied (nominal or ordinal, continuous or categorical, quantitative or qualitative). Traditional models, such as analysis of variance, log linear, and logistic regression were not able to address these issues. Instead, random forests model can simultaneously handle these challenges (Breiman, Cutler 2007; Moisen 2008). Random forests is a tree-based model that tends to have lower variance by taking repeated samples from a single data set and combining them together. Thus, random forests model includes a very large number of decision trees. Thus, the interpretation of random forests is awkward (James et al. 2013). To address this challenge, the variable importance measure is provided for random forests model. A greater importance value indicates that the predictor has a more significant role in the response.

Since predictors were measured with their own units, the authors also conducted a standardization of predictors to avoid the possible bias caused by a varied scale. To do this, a standard transformation was conducted, each variable subtracted its mean and divided by standard error. After standardization, the measurements of all predictors ranged from -1 to +1 . Then, a random forests package was created in $\mathrm{R}$ Development Core Team (2014). The subset of variables considered in each splitting is suggested to be $m=\sqrt{p}$ (James et al. 2013). For this study, having 6 explanatory variables, including sign color, length, width, mount height, land cover, and road type, m equals three was considered. No particular rule or optimal number is suggested for the number of trees in the literature, although a larger number of trees did not lead to consistently better performance (Oshiro et al. 2012). For the current study, 1500 trees were developed, which is an appropriate number for such sample sizes. After obtaining the variable importance values from developing random forests model, importance values were normalized to make interpretation easier (Fig. 6). This was designed so that the most important predictor had an importance of 100 (Rebollo, Balakrishnan 2014).

\section{Discussion}

As seen in Fig. 6, although all sign attributes were important to vandalism rates, the height of sign above the road was, by far, the most important variable. The importance of sign mount height reflects the fact that regardless of sign color, size and localized conditions, vandalism damage on the face of traffic signs is more frequent on ground mount signs. Despite this, the strong

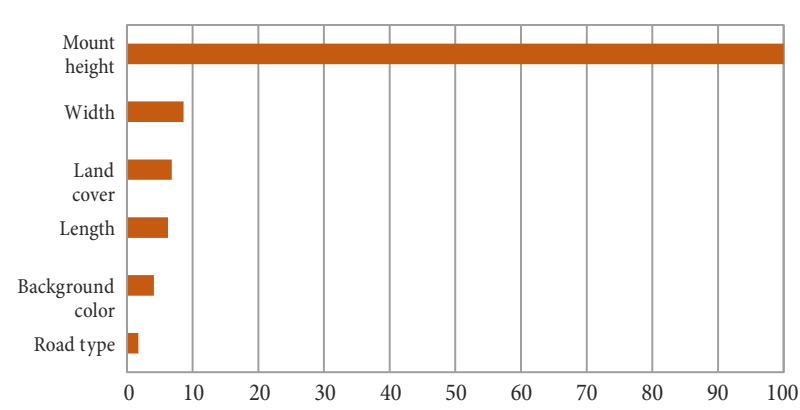

Fig. 6. Variable importance ranking for traffic sign vandalism

association between mount height and vandalism rate did not seem to be linear because the rate of vandalism for signs installed within 5 feet of the ground was less than those between 5 and 7 feet. While the average mount height for all measured signs was about 8 feet, the average height of vandalized signs was 6.5 feet above the road. The closeness of rankings of sign size, color, land cover, and road type may indicate an inner correlation or interaction between those predictors. To enable more in-depth analysis, the possible interaction between the most important variable, sign mount height, and other factors should be studied. Fig. 7 shows the Pearson correlation coefficient values (the covariance of the two variables divided by the product of their standard deviations). As seen in the figure, significant correlation between sign width and sign length is evident. The correlation between other variables was not significant.

As shown in Fig. 8, approximately, all of the vandalized signs located in rural areas or installed on ramps had a mount height less than 10 feet. Thus, mounting these signs higher can be a good countermeasure against sign vandalism. In addition, 53\% of vandalized signs were warning signs. Turn and curve warning signs that comprised approximately $30 \%$ of vandalized signs, have an average mount height of 6.6 feet with 1.5 standard deviation.

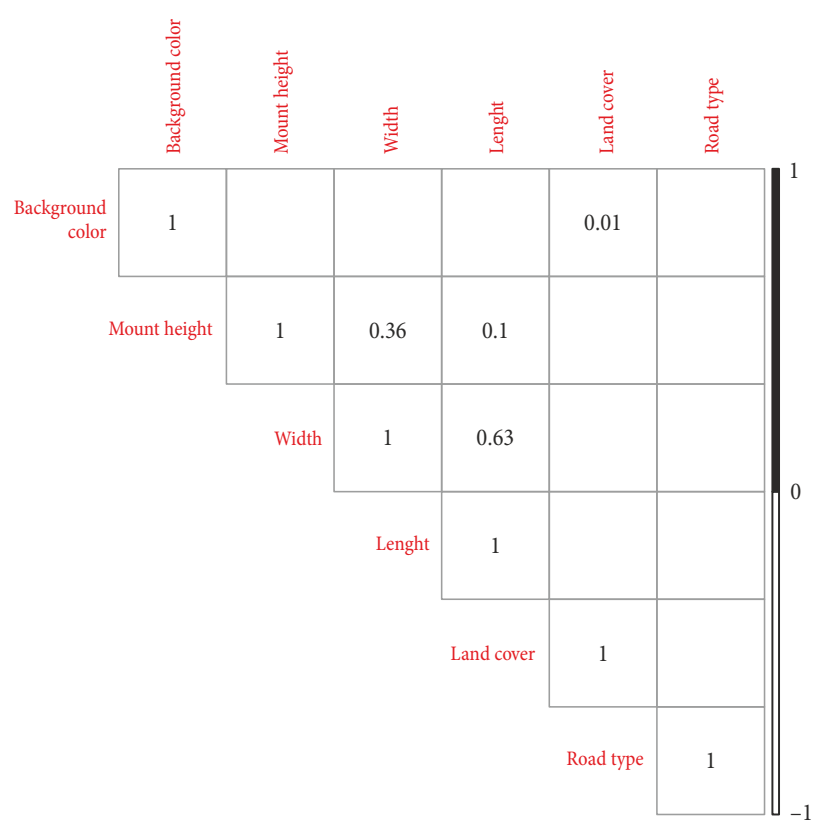

Fig. 7. Pearson correlation coefficient values 

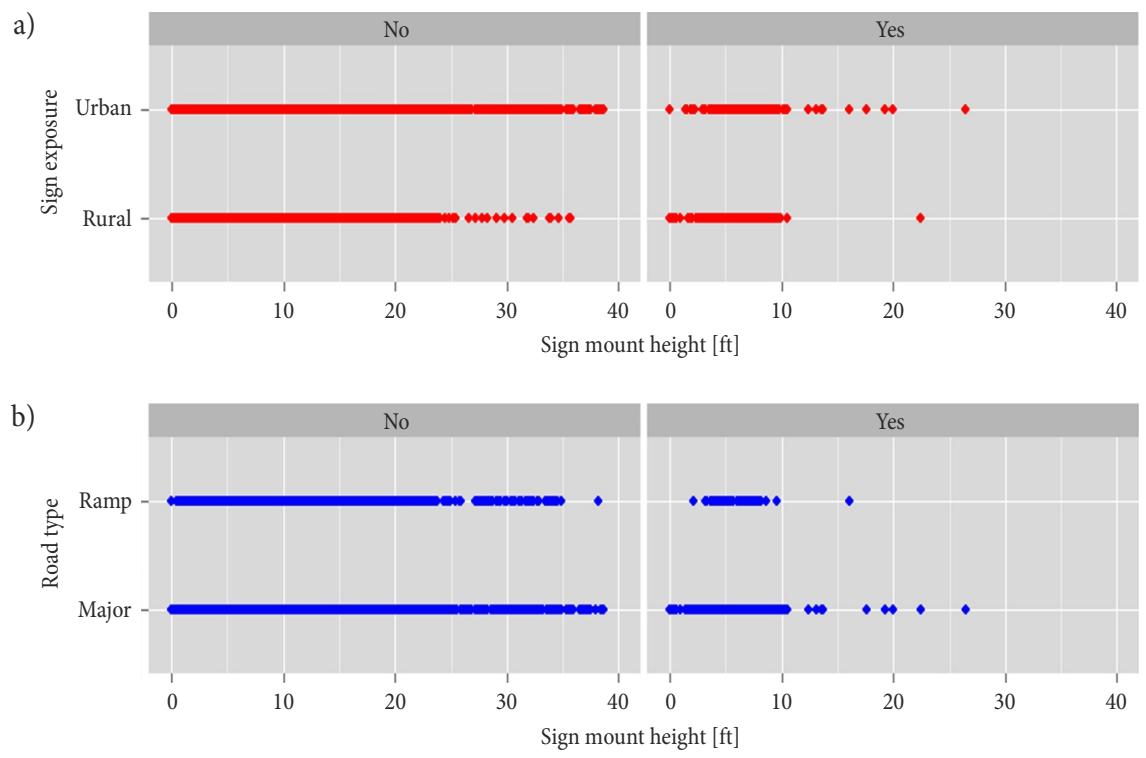

Fig. 8. Vandalized signs by mount height vs. (a) exposure and (b) road type

As a result, warning signs can also be mounted higher. However, most of warning signs are located on minor or local roads. Taking into consideration the signs located on ramps or in rural areas, increasing sign heights may dramatically affect sign visibility (especially during hours of darkness) since headlights will not reach higher sign heights. To address this issue, traffic signs can be equipped with internal or external lightening systems.

\section{Conclusions}

Traffic sign vandalism is a serious concern, since it causes a decline in the overall legibility and visibility of signs. Such events can lead to an increase in unsafe driving behaviors. It also results in increased costs to transportation agencies to replace, repair, or maintain the vandalized signs. This paper examined the association between vandalism rates and the traffic sign attributes and localized conditions, including sign background color, size (length and width), mount height, exposure, land cover, and road type. Initial analysis showed that warning signs had the highest vandalism rates. After further analysis, and according to the chi-square test results, the association between sign attributes and vandalism was evident. After employing random forests model, the ranking of the predictors on the rate of traffic sign vandalism was also extracted.

In case of considering countermeasures against sign vandalism, the findings of this study showed that priority given to turn and curve signs (W1 series), object markers (OM series), advance warning/crossing signs (W11 series), and speed regulation (R2 series) is warranted. Since the height of sign above the road was, by far, the most important factor, one suggestion is to install more vulnerable signs to vandalism higher above the road. To address the issue of being outside of lighted areas by headlights, traffic signs can be equipped with internal or external lightening systems. In this way, the evaluation of cost effectiveness of labor and material to do countermeasures against vandalism is the next step that should be taken.

The findings of this investigation may assist transportation agencies in determining traffic signs with a higher likelihood of sign vandalism based on sign attributes. Based on our findings, transportation agencies' policies could be changed to considering countermeasures against vandalism (before sign installation) and more frequent inspection (after sign installation) of the following traffic signs:

- signs with mount height between five and seven feet;

- signs placed in rural or low intensity urban areas, in particular, signs installed in areas with land cover labeled as forest;

- signs installed in roads with lower traffic, such as ramps.

\section{Acknowledgements}

We would like to express our deepest thanks to UDoT for sponsoring data collection. We would also like to express thanks to Mandli Communications Inc. for collecting data. The GIS data was obtained with the assistance of Dr. David Tarboton. This assistance is gratefully acknowledged. The authors would also like to convey their gratitude to Wesley Boggs, Travis Evans, and Kevin Gardiner who took photos of traffic signs in the field.

\section{References}

Balali, V.; Golparvar-Fard, M. 2015. Segmentation and recognition of roadway assets from car-mounted camera video streams using a scalable non-parametric image parsing method, Automation in Construction 49(A): 27-39. http://doi.org/10.1016/j.autcon.2014.09.007

Baratian-Ghorghi, F.; Zhou, H.; Jalayer, M.; Pour-Rouholamin, M. 2015. Prediction of potential wrong-way entries at exit ramps of signalized partial cloverleaf interchanges, Traffic Injury Prevention 16(6): 599-604. http://doi.org/10.1080/15389588.2014.981651 
Boggs, W.; Heaslip, K.; Louisell, C. 2013. Analysis of sign damage and failure: Utah case study, Transportation Research Record: Journal of the Transportation Research Board 2337: 83-89. http://doi.org/10.3141/2337-11

Borowsky, A.; Shinar, D.; Parmet, Y. 2008. Sign location, sign recognition, and driver expectancies, Transportation Research Part F: Traffic Psychology and Behaviour 11(6): 459465. http://doi.org/10.1016/j.trf.2008.06.003

Breiman, L.; Cutler, A. 2007. Random Forests. Department of Statistics, University of California, Berkeley. Available from Internet: https://www.stat.berkeley.edu/ breiman/ RandomForests/cc_home.htm

Bullough, J. D.; Skinner, N. P.; O’Rourke, C. P. 2010. Legibility of urban highway traffic signs using new retroreflective materials, Transport 25(3): 229-236. http://doi.org/10.3846/transport.2010.28

Chadda, H. S.; Carter, E. C. 1983. Sign vandalism: time for action-now, ITE Journal 53(8): 16-19.

DoT. 2012. Manual on Uniform Traffic Control Devices. Department of Transportation (DoT), Federal Highway Administration, US. Available from Internet: http://mutcd. fhwa.dot.gov

Ellis, R.; Houten, R.; Kim, J.-L. 2007. In-roadway "yield to pedestrians" signs: placement distance and motorist yielding, Transportation Research Record: Journal of the Transportation Research Board 2002: 84-89. http://doi.org/10.3141/2002-11

Ellison, J. W. 1996. "Stop and think": a campaign against traffic vandalism, in Compendium of Technical Papers for the 66th ITE Annual Meeting, 15-18 September 1996, Minneapolis, Minnesota, US, 259-260.

Evans, T.; Heaslip, K.; Boggs, W.; Hurwitz, D.; Gardiner, K. 2012. Assessment of sign retroreflectivity compliance for development of a management plan, Transportation Research Record: Journal of the Transportation Research Board 2272: 103-112. http://doi.org/10.3141/2272-12

Harris, G. 1992. Engineering Study for Reducing Sign Vandalism. Final Report. Highway Research Advisory Board Project HR-246. Iowa Department of Transportation, Ames, Iowa, US. Available from Internet: http://publications.iowa. gov/13439

James, G.; Witten, D.; Hastie, T.; Tibshirani, R. 2013. An Introduction to Statistical Learning: with Applications in $R$. Springer. 426 p. http://doi.org/10.1007/978-1-4614-7138-7

Khalilikhah, M.; Heaslip, K. 2016a. Important environmental factors contributing to the temporary obstruction of the sign messages, in TRB 95th Annual Meeting Compendium of Papers, 10-14 January 2016, Washington, DC, US, 1-13.

Khalilikhah, M.; Heaslip, K. 2016b. GIS-based study of the impacts of air pollutants on traffic sign deterioration, in TRB 95th Annual Meeting Compendium of Papers, 10-14 January 2016, Washington, DC, US, 1-15.

Khalilikhah, M.; Heaslip, K.; Hancock, K. 2016. Traffic sign vandalism and demographics of local population: a case study in Utah, Journal of Traffic and Transportation Engineering (English Edition) 3(3): 192-202. http://doi.org/10.1016/j.jtte.2015.11.001

Khalilikhah, M.; Heaslip, K.; Louisell, C. 2015a. Analysis of the effects of coarse particulate matter (PM10) on traffic sign retroreflectivity, in TRB 94th Annual Meeting Compendium of Papers, 11-15 January 2015, Washington, DC, US, 1-16.

Khalilikhah, M.; Heaslip, K.; Song, Z. 2015b. Can daytime digital imaging be used for traffic sign retroreflectivity compliance?, Measurement 75: 147-160.

http://doi.org/10.1016/j.measurement.2015.07.049
Ma, J.; Smith, B. L.; Fontaine, M. D. 2016. Comparison of invehicle auditory public traffic information with roadside dynamic message signs, Journal of Intelligent Transportation Systems 20(3): 244-254.

http://doi.org/10.1080/15472450.2015.1062729

Moeur, R. C. 2014. Manual of Traffic Signs. Available from Internet: http://www.trafficsign.us

Moisen, G. G. 2008. Classification and regression trees, in S. E. Jørgensen, B. D. Fath (Eds.). Encyclopedia of Ecology, 582588. http://doi.org/10.1016/B978-008045405-4.00149-X

MRLC. 2011. National Land Cover Database 2011 (NLCD 2011). Multi-Resolution Land Characteristics (MRLC) consortium. Available from Internet: http://www.mrlc.gov/ nlcd2011.php

Mueller, G. 1995. Sign Vandalism Detection. Report No SPRUAF-92-22F. Alaska Department of Transportation and Public Facilities, US. 21 p. Available from Internet: http:// www.dot.state.ak.us/stwddes/research/assets/pdf/ine_ trc_94_16.pdf

Oshiro, T. M.; Perez, P. S.; Baranauskas, J. A. 2012. How many trees in a random forest?, Machine Learning and Data Mining in Pattern Recognition 7376: 154-168.

http://doi.org/10.1007/978-3-642-31537-4_13

Perkins, D. D; Barton, M. J. 1997. Traffic Signing Handbook. Chapter 15. Vandalism Control. Institute of Transportation Engineers (ITE), Washington, DC, US, 227-236.

Picha, D. 1997. Texas sign vandals still leaving mark, Texas Transportation Researcher 33(2): 6-7.

R Development Core Team. 2014. R: a Language and Environment for Statistical Computing. The R Foundation for Statistical Computing. Vienna, Austria. Available from Internet: http://www.r-project.org

Ré, J. M.; Carlson, P. J. 2012. Practices to Manage Traffic Sign Retroreflectivity. TRB's National Cooperative Highway Research Program (NCHRP) Synthesis 431. Transportation Research Board, Washington, DC, US. 44 p. Available from Internet: http://doi.org/10.17226/14663

Rebollo, J. J.; Balakrishnan, H. 2014. Characterization and prediction of air traffic delays, Transportation Research Part C: Emerging Technologies 44: 231-241. http://doi.org/10.1016/j.trc.2014.04.007

Smith, D.; Simodynes, T. 2000. Sign vandalism - an estimate of the national cost, in Mid-Continent Transportation Symposium 2000, 15-16 May 2000, Ames, Iowa, US, 245-248. Available from Internet: http://www.ctre.iastate.edu/pubs/ midcon/smith.pdf

Stanić, B.; Vujin, D. 2005. New aesthetics of the city - design of cyclists traffic signs, Transport 20(6): 257-264.

Strawderman, L.; Rahman, M. M.; Huang, Y.; Nandi, A. 2015. Driver behavior and accident frequency in school zones: assessing the impact of sign saturation, Accident Analysis \& Prevention 82: 118-125. http://doi.org/10.1016/j.aap.2015.05.026

Utah AGRC. 2015. Most Popular Datasets. Utah Automated Geographic Reference Center (AGRC). Available from Internet: https://gis.utah.gov/data

VDoT. 2011. Virginia Standard Highway Signs. Virginia Department of Transportation (VDoT). 208 p. Available from Internet: http://www.virginiadot.org/business/resources/ ted/final_mutcd/standard_highway_signs_book.pdf

Ye, F.; Carlson, P. J.; Brimley, B. K. 2014. Applying the sign luminance computation model to study the effects of other vehicles on sign luminance, Transport 29(2): 115-124. http://doi.org/10.3846/16484142.2014.927396 